\title{
UNA RECUPERACIÓN: LAS SEMANAS DEL JARDÍN, DE MIGUEL DE CERVANTES
}

Cervantes solía anunciar, con diversa antelación, los libros que estaba componiendo y que tenía intención de editar. Así, en La primera parte de La Galatea, promete la continuación de este libro de pastores: «El fin deste amoroso cuento y historia [...] con otras cosas sucedidas a los pastores hasta aquí nombrados, en la segunda parte desta historia se prometen, la cual, si con apacibles voluntades esta primera viere recibida, tendrá atrevimiento de salir con brevedad a ser vista y juzgada de los ojos y entendimiento de las gentes" '. La brevedad, en cuanto se refiere al término de su aparición, señalada en la cita, no se cumplió, aunque se trata de uno de los proyectos más largamente acariciados por el autor y que se reitera en diversos lugares de su obra, como sucede en el escrutinio de la librería de don Quijote, donde se señala al juzgar la primera parte que ues menester esperar la segunda parte que promete" ${ }^{2}$, tras indicar que el «libro tiene algo de buena invención; propone algo, y no concluye nada" ${ }^{3}$. Nuevas promesas se incluyen en la dedicatoria al conde de Lemos, al frente de sus Ocho comedias y ocho entremeses: "Luego irá el gran Persiles, y luego Las semanas del jardin, y luego la segunda parte de La Galatea, si tanta carga pueden llevar mis ancianos

1 Miguel De Cervantes, La Galatea, ed. Juan Bautista Avalle-Arce, Madrid, Espasa Calpe, 1961, II, p. 266. Las referencias a la prometida continuación de La Galatea se encuentran resumidas en AMÉRICo CASTRO, El pensamiento de Cervantes, ed. del autor y de Julio Rodríguez Puértolas. Barcelona, Noguer, 1980, pp. 64-65, nota 44.

2 Miguel De Cervantes, Don Quijote de la Mancha, ed. Martín de Riquer. Barcelona, Planeta, 1975, p. 80.

3 Ibid. 
hombros» " y en el prólogo a la segunda parte del Quijote: "Olvídaseme de decirte que esperes el Persiles, que ya estoy acabando, y la segunda parte de Galateas s. En la trágica dedicatoria al Persiles vuelve a recordar su Galatea inconclusa: "Si a dicha, por buena ventura mía, que ya no sería ventura, sino milagro, me diese el cielo vida, las verá, y con ellas fin de la Galatea, de quien sé está aficionado vuesa Excelencia” ${ }^{\circ}$.

Conforme hemos ido siguiendo el hilo de la promesa de la continuación de su libro pastoril, han ido apareciendo referencias a otras obras que Cervantes estaba componiendo. Algunas de esas obras prometidas por Cervantes no vieron la luz de la imprenta en vida del autor; esto ocurre con el Persiles, que se publicó al año siguiente de su muerte, en otras ocasiones las obras no han podido localizarse, si es que se escribieron en su integridad, y es preciso darlas por perdidas, como ocurre con el Bernardo, mencionado en la dedicatoria del Persiles: "Todavía me quedan en el alma ciertas reliquias y asomos de las Semanas del jardín, y del famoso Bernardon ?. Sin embargo, también puede ocurrir que logren encontrarse, ampliando de ese modo el magno universo cervantino. Éste es posiblemente el caso de Las semanas del jardín.

La última referencia del propio autor a esta obra, cuyo título retomaría luego Rafael Sánchez Ferlosio para un experimento narrativo sumamente complejo ${ }^{8}$, se encuentra en el mencionado lugar del Persiles. También se cita en el prólogo a las Novelas ejemplares, donde promete igualmente el Persiles y la continua-

4 Miguel de Cervantes, Comedias y entremeses, ed. Rodolfo Schevill y Adolfo Bonilla. Madrid, Imprenta de Bernardo Rodríguez, 1915, tomo I, p. 11; grafía actualizada.

${ }^{5}$ Miguel de Cervantes, Don Quijote de la Mancha, op. cit., p. 577.

- Miguel de Cervantes, Los trabajos de Persiles y Sigismunda, ed. Juan Bautista Avalle-Arce. Madrid, Castalia, 1969, p. 46.

${ }^{7}$ El profesor Eisenberg piensa que el Bernardo pudo ser el libro de caballerías de Cervantes, en torno a Bernardo del Carpio; cfr. DANIEL EISENBERG, «El Bernardo de Cervantes fue su libro de caballerías», Anales Cervantinos, 21, 1983, pp. 103107, y del mismo autor, A Study of "Don Quijote". Newark, Delaware, Juan de la Cuesta, 1987, cap. II, "The Ideal Libro de caballerias: The Bernardon, pp. 4577. No parece descabellada la idea, sobre todo si tenemos en cuenta que Bernardo del Carpio es una creación de los ingenios españoles para oponerlo a los personajes de raigambre francesa, como Orlando, y en torno a él se gestarían algunas obras como la segunda parte, también perdida, de la Angélica de Luis Barahona de Soto, cfr. EsTHER LACADENA, Nacionalismo y alegoría en la épica española del siglo XVI: "La Angélica" de Luis Barahona de Soto. Zaragoza, Universidad, 1980.

8 Rafael Sánchez Ferlosio, las semanas del jardín. Semana primera: Liber scriptus proferetur. Madrid, Nostromo, 1974, y Las semanas del jardín. Semana segunda: Splendet dum frangitur. Madrid, Nostromo, 1974; otra edición, Las semanas del jardin. Madrid, Alianza, 1981. 
ción del Quijote: «y primero verás, y con brevedad dilatadas, las hazañas de don Quijote y donaires de Sancho Panza, y luego las Semanas del jardín ' ${ }^{9}$ Y, tal como señalábamos en las referencias al libro pastoril, aparecen otra vez las promesas de estas obras, junto con el Persiles, en los preliminares de su teatro. De esas menciones parece desprenderse, por una parte, la decidida intención de Cervantes de componer la obra; por otra, el orden aproximado de aparición: Persiles, Semanas, Galatea (el Bernardo se intercala en una sola ocasión y quizás fuese un proyecto poco perfilado); por último, la posibilidad de que hubiese compuesto parte de la misma, de la que aún le "quedan en el alma ciertas reliquias y asomos", seguramente restos de ideas, bocetos, señales, que engrosarían el material ya elaborado, aunque no completamente pulido y rematado, tal como se advierte en la parte final de su libro póstumo.

La atribución inicial de este fragmento al autor del Quijote fue obra de Adolfo de Castro en un libro sumamente controvertido, Varias obras inéditas de Miguel de Cervantes (1874). Sin duda, la poca credibilidad de que gozaba Castro entre los círculos intelectuales de su época, debida sobre todo a la edición de un texto atribuido a Cervantes, titulado El buscapié y que luego se reveló una especie de divertimiento o de broma, una falsificación en suma, hizo que numerosos eruditos dudasen de la autenticidad de las piezas incluidas en el volumen citado. Con todo, en diversas ocasiones, y tal como puede verse en el apéndice del profesor Eisenberg a la edición que comentamos ${ }^{10}$, algunos estudiosos estuvieron de acuerdo con la atribución, como Menéndez Pelayo, entonces muy joven, o José María Asensio. Más numerosos son los críticos que se oponen a la atribución cervantina, entre los que pueden recordarse a Amezúa o a Astrana Marín. Optan otros por una prudente interrogación, como el profesor López Estrada, que volvió a reeditar y a estudiar el fragmento, refiriéndolo a una situación relacionada con el mundo pastoril y

9 Miguel de Cervantes, Novelas ejemplares, ed. Juan Bautista Avalle-Arce, Madrid, Castalia, 1982, I, p. 65. La misma cita, con idéntica puntuación, en la edición de Harry Sieber, Madrid, Cátedra, 1989, I, p. 53; pero parece más correcto, de acuerdo con el sentido que creemos percibir en la frase, puntuar: "y primero verás, y con brevedad, dilatadas las hazañas de don Quijote y donaires de Sancho Panzaw, en referencia a la brevedad temporal en orden a la aparición próxima de la segunda parte del Quijote, en el que se encontrarán dilatadas o ampliadas las hazañas de los personajes.

10 Daniel Eisenberg, Las "Semanas del jardin" de Miguel de Cervantes, estudio, edición y facsímil del manuscrito. Salamanca, Ediciones de la Diputación, 1988 [1989], 194 pp. En las citas tomadas de esta edición se indica en el cuerpo de la reseña, a continuación de la cita, el número de la página correspondiente. 
titulándolo, tal como se ha hecho en la mayoría de las ocasiones, Diálogo de Cillenia y Selanio ".

Esta edición de Las semanas del jardín, de Miguel de Cervantes, ha sido preparada por el profesor Daniel Eisenberg, de la Universidad Estatal de la Florida, y puede calificarse como una edición modélica. Consta de un extenso estudio introductorio, el texto crítico, compuesto por unas quince páginas, un apéndice en el que se estudia la crítica generada por la obra, junto con el facsímil de la misma, que se guarda en la Bilbioteca Colombina; un útil índice de nombres cierra el volumen.

El rigor filológico empleado, el complejo mundo de relaciones con las obras que forman el corpus cervantino conocido, la persecución de los temas que integran el entramado del diálogo, junto con numerosas referencias de carácter comparativo, dan como resultado un cuadro sumamente coherente $y$, en consecuencia, convincente en líneas generales, de tal manera que existe, de acuerdo con el amplio estudio introductorio, un alto índice de probabilidad de que el texto editado sea obra de Cervantes, aunque no pueda tenerse la seguridad completa y absoluta con respecto a tal identificación, aun cuando el fragmento nunca se haya atribuido a ningún otro autor. De esta forma puede afirmarse que el análisis literario y filológico llega aquí a los límites de su valor probatorio; más allá se entraría en el campo de lo meramente especulativo.

Entre los aspectos que contribuyen a dar una apariencia más problemática a la obra se encuentra su fragmentarismo. El carácter fragmentario del texto se advierte en las referencias internas existentes al principio y al final de la parte conservada. Selanio dice a Cillenia: "Con grandísimo deseo he vivido, discreta y hermosa señora mía, de saber cómo os habéis hallado con la verdad, y lo que della os ha parecidon (p. 145), fórmulas que sirven para enlazar con lo que ya se ha dicho, que trataría acerca de la verdad, y que se retoma y comenta a continuación. La dama responde, entre otras cosas: «La operación y efecto que en mí ha hecho [la verdad] es dejarme escandalizada y espantada, como a vos os dejó, de ver el engaño en que hasta aquí había

1 Francisco LÓpez Estrada, "Estudio del Diálogo de Cillenia y Selanion, Revista de Filología Española, 57, 1974-1975, pp. 159-194 y «Estudio del Diálogo de Cillenia y Selanion, Actas del quinto congreso internacional de hispanistas. Bordeaux, 1977, II, pp. 603-609 (se trata de estudios distintos: el segundo es un resumen del primero). Tras la edición de Eisenberg, López Estrada continúa manifestando cierto escepticismo en cuanto se refiere a aceptar de manera definitiva la identificación de este texto con un fragmento de Las semanas del jardin; cfr. Francisco López Estrada, "Las fronteras de Cervantes: ¿Las Semanas del jardín restituidas? "Insula, 516, diciembre 1989, p. 4. 
vivido, teniendo por gente sencilla, verdadera y casi santa a quien dentro de sí encerraba tan enormes fraudes y engaños como la verdad descubre" (p. 147), y en sus palabras se advierte la reflexión sobre uno de los temas tratados (¿hay aquí una referencia enmascarada a la hipocresía de algunos religiosos, que recuerda ideas parecidas del pensamiento erasmista? La cuestión resurge en alguna ocasión en el discurso de Selanio, aunque con la misma vaguedad en el referente: "Otros hay que con hipocresías fingidas se quieren hacer estimar por virtuosos, caritativos $y$ santos, y que les da grandes aldabadas el deseo de la virtud y que.todos la sigan", etc., pp. 152-153). Más adelante Cillenia se refiere de nuevo a lo tratado: "holgaré que vos me digáis las causas y razones que vos halláis para elegir y tener por mejor la vida solitaria y no la civil y cortesana, como estotro día en la conversación de la huerta nos distes a entender, que no solamente a mí, más a las damas que allí se hallaron, les pareció novedad en un hombre cortesano y criado toda la vida en la corte como vos" (p. 149). Igualmente queda abierto el final: Cillenia invita a Selanio a tratar del aspecto positivo de la vida de la corte, tras la hermosa recreación y evocación de la vida del campo, diciéndole: "cuando en buen hora volváis acá otro día" (p. 159), invitación que Selanio acepta; «Si del todo no se me acaba [la ventura de estar en la compañía de la dama] tomaré otro día la tarde más temprano" (ibíd.).

A pesar de tratarse de un fragmento, el texto tiene sentido completo y se ocupa fundamentalmente de hacer una alabanza de la vida del campo, buscando en el espacio rústico "con mayor y más segura tranquilidad gozar de vida sosegada y quieta" (p. 151). Los ecos del beatus ille horaciano impregnan la hermosa defensa de Selanio, centrada en el mundo idílico y pastoril de la edad de oro: "digo, señora mía, que al que se puede llamar venturoso, y tener envidia a su estado y tranquilidad de su ánimo, es al hombre que, dándose a la moral filosofía, y viviendo como cristiano filósofo, se contenta con lo que le da la naturaleza, y tiene conocimiento de las causas por sus efectos, y de tal suerte está prevenido, que ningún caso que le suceda, próspero ni adverso, le altera, admira ni espanta, teniendo las cosas por venir como presentes, y las presentes como pasadas, porque este tal tiene conocimiento de sí mismo, y cumpliendo por lo menos con la ley natural, quiere para los otros lo que para sí. Mas al que en mi opinión, discreta Cillenia, yo tuviera envidia y tuviera por sumamente feliz, es aquel cuyas descuidadas plantas pisan sin sobresalto ni congoja la verde hierba de los prados, y pasean las frescas riberas de los corrientes ríos, si llega a tener conocimiento 
de su estado, y levanta el ánimo y espíritu a considerar la tranquilidad de lo que posee, y ejercitado en rústico y silvestre ejercicio, no tiene cuenta ni le desasosiegan los tráfagos, bullicios y negociaciones de las ciudades, ni respeta a nadie por temor, ni le tiene a las olas y fortunas del poblado, ni se halla obligado a la pesada carga del cumplimiento que tanto muele a quien no cae en la cuenta de su pesadumbre. Antes libre destas cosas, suelto y desembarazado, con el arco en la mano, la ballesta al hombro y el aljaba y carcaj al cuello, y el zurrón con la pobre y sabrosa comida al lado, cruza y atraviesa los montes, valles y setos, sin que le impidan los ríos ni aspereza de montañas a seguir y perseguir la caza, sustentando su cabaña de la que cada día mata, recreando y regocijando su ánimo con esparcir por el aire, al son de su rabel o mal compuesta zampoña, sus rústicas cantilenas, tomando sabor y gusto de mirar las silvestres luchas de los toros y de los roncos bramidos que van dando los vencidos, y del manso rumiar de las mansas ovejas y el descuido con que pacen la verde y menuda hierba, y del recatado sueño de los mastines que las guardan y defienden de los dañosos lobos. Huélgase de ver los retozos y sueltas y ligeras cabriolas de los cabritillos, y las madres encaramadas en las encinas. Conténtase con cubrir su fuerte, sano y bien ejercitado cuerpo con las pieles de sus ganados, y echarse debajo de frondosos árboles. Satisface a la hambre y necesidad corporal con las silvestres frutas que dellos coge, sembrando la hierba que tiene por mesa de las bellotas, castañas y nueces que con sus brazos derrueca, con que queda más satisfecho y contento que los príncipes y señores con la diversidad de viandas que sirven en sus curiosas mesas, porque come con hambre, y tiene siempre consigo la salsa de San Bernardo, y le falta tampoco la blanca y sabrosa leche con que remoja el duro pan que trajo del aldea" (pp. 155-156). Las reflexiones continúan desarrollando diversos aspectos de la vida del campo. El discurso de Selanio, independientemente de su aspecto cervantino y de su valor como tal, es un fragmento bellísimo, comparable y quizás superior a cualquier otro de nuestra literatura que toque el mismo tema y que merece conocerse por sus valores intrínsecos; es posible que casi ningún escritor, salvo Cervantes, como indica Eisenberg ${ }^{12}$, pudiese crear

12 «Para nosotros, y no queremos imponer nuestra opinión a nadie, es uno de los más hermosos escritos que hayamos leído nunca, comparable en su efecto sólo al prólogo al Espejo de príncipes, otro texto de derivación petrarquesca, que Cervantes conocía. Este fragmento supera en mucho dicho prólogo. Parece lógico atribuir a un gran autor un texto de notable calidad literariaw, DANIEL EISENBERG, Las "Semanas del jardin" de Miguel de Cervantes, op. cit. p. 29. 
un texto parecido. Por otra parte, como puede advertirse en el fragmento señalado, el ritmo de la frase evoca en la mente de un lector habitual de Cervantes, de manera vaga e indefinible, el estilo del autor del Quijote, su madurez, su soltura, su enorme experiencia humana. Con todo, el tema ha sido tratado con bastante frecuencia en nuestra literatura y aparece en los lugares más insospechados. Una visión de la vida pastoril, que presenta algunos rasgos parecidos, la encontramos en una obra de inspiración cervantina, Los trabajos de Narciso y Filomela, de Vicente Martínez Colomer, narración inédita por ahora y compuesta en fecha muy tardía, en el último tercio del siglo XVIII, hacia 1784. En ella un personaje pretende dar una visión idealizada de la vida del pastor, distinta de la versión literaria de los libros de pastores, aunque en el fondo está latente, como en el texto de Las semanas del jardín, el mito de la edad de oro: "Yo no sé, hermano - proseguía Constanza-, qué cuidados, qué inquietudes, qué guerras interiores puedan tener estos humildes hombres, para que sea su vida desacomodada como dices, cuando todo su afán se cifra en sólo el cuidado de sus ganados. No bien sale el sol para alegrar con sus hermosos rayos a todas las criaturas, cuando libre de todo molesto cuidado se levanta el pastor alegre, empuña su cayado, tira por los hombros a la espalda su zurrón proveído de sabrosos aunque rústicos manjares, llama a sus simples ovejas y empieza su deliciosa y ordinaria tarea; pero, ¿con cuánta alegría de su alma? El armonioso y entretenido espectáculo que forman el azul hermoso del cielo con el verde piso de la tierra, le tiene todo el día en alegre suspensión. Los campos, primorosamente matizados de plantas, flores, frutos, quintas, bosques y sotos, son el más curioso entretenimiento de sus sentidos. Todos están en continuo movimiento sin parar de percibir, ni por un breve rato, su recreación correspondiente. Aquí divierte su vista con la hermosura de los árboles, con el verdor de las plantas, con la belleza de las flores; allí recrea el oído con el manso ruido de los arroyos, con el apacible susurro que forman las hojas de los árboles heridas de los más suaves vientecillos y con la agradable armonía de los infinitos pajarillos, que por entre aquellos bosques hacen ostentación de la dulzura de sus voces; allá recrea el olfato con el olor que despide la azucena, el lilio, la violeta, el clavel, la rosa y las muchas yerbas aromáticas que produce la tierra; acullá lisonjea su gusto con probar los frutos 
que penden de las ramas de los árboles, y el tacto le recrea con la suavidad de tantos objetos como a cada paso se le ofrecen" ${ }^{13}$.

Uno de los aspectos más interesantes de Las semanas es, sin duda, la estructura dialógica de la obra. El diálogo español, que hasta hace poco tiempo carecía de un buen estudio de conjunto ${ }^{14}$, tiene aquí una muestra representativa y con todo el interés que se deriva de la consideración del mismo como obra cervantina; de Cervantes conocíamos la maestría insuperable y la fluidez de los diálogos del Quijote, siendo paradigmáticos los de don Quijote y Sancho, pero se desconocía un diálogo puro, teniendo en cuenta que en el Coloquio de los perros, que presenta

${ }^{13}$ El fragmento completo, relativo a la vida pastoril, en el que se pueden encontrar diversos paralelismos de contenido con el señalado en las Semanas, está editado; cfr. ANTONIO CRUZ CASADO, «El viaje como estructura narrativa: Los trabajos de Narciso y Filomela, de Vicente Martínez Colomer, una novela inédita (presentación y textos)m, Arcadia. Estudios y textos dedicados a Francisco López Estrada, Dicenda. Cuadernos de Filología Hispánica, 7, 1988, pp. 309-325. Una edición completa de la obra aparecerá en la Colección Cervantina de la Editorial Anthropos.

${ }^{14} \mathrm{Cfr}$. ahora el buen estudio de Jesús GÓmez, El diálogo en el Renacimiento español Madrid, Cátedra, 1988. En el mismo aparece alguna referencia aislada al Diálogo entre [sic] Cillenia y Selanio sobre la vida del campo; por ejemplo, en la p. 34, situándolo en un contexto de alabanza del mundo pastoril. En el com. plejo catálogo bibliográfico, inserto al final de la obra, no encuentro mención del inédito y curioso Diálogos de la juventud enamorada aunque este texto puede considerarse algo más tardio, quizás del primer tercio del siglo XVII. La obra, incluida en el ms. 17563, de la Bilbioteca Nacional de Madrid, parece no haber sido estudiada. El nombre del autor aparece al final del texto: Francisco María Cassiano. Se inicia con un escrito en el que el autor del libro habla con él, interesante recurso que sugiere otros cervantinos parecidos [Cervantes escribe un soneto, «El autor a su pluma» en los preliminares del Viaje del Parnaso], y sigue otro prólogo a los «Diálogos familiares de juventud enamoradaw. El contenido general ofrece un carácter moral y religioso, con referencias al amor y sus tipos, a la concupiscencia y a la amistad; son wlos sucesos enamorados de cuatro amigos y los consejos de un sabio viejo a quien al cabo escuchan a reducirnos a escarmiento y cordura y amor del prójimon (f. $10 \mathrm{r}$, grafía actualizada). Son cinco diálogos en los que participan Felicio, Claudio, Alejandro y Ricardo. En el primero Felicio se refiere a umi querida patria Madrid» y dicen encontrarse a nueve leguas de esta ciudad, f. 30 v. Aparecen referencias a tradiciones madrileñas, como la de Santiago el Verde, f. $21 \mathrm{v}$, y se intercalan poemas de no mala factura; así encontramos un soneto misógino, "Albornocio contra las mujeres", f. $23 \mathrm{r}$, y otro amoroso, «Albornocio por Celia, f. 25 v y ss. Cada diálogo incluye además una historia de carácter amoroso que afecta a los personajes y que ocupa gran parte del texto, de tal manera que el diálogo se convierte en el marco de las narraciones: en el primero se cuentan los sucesos amorosos de Alejandro, en el segundo los de Orsino, en el tercero los amores de Felicio y en el cuarto los sucesos de Claudio; parte de la acción de este último episodio tiene lugar en Sevilla. En el diálogo quinto no hay historia propiamente y en su lugar aparecen las reflexiones morales del anciano Archifebo. Las composiciones son numerosas, como las dedicadas a los ríos Manzanares, Tajo, Pisuerga y Tormes. 
una estructura dialógica, resalta especialmente su carácter narrativo y como tal se incluye en la colección de novelas ejemplares. Como se sabe, el género fue una forma literaria bastante cultivada en la literatura española áurea y dio origen a diversas obras maestras. La mayoría de estas obras fueron editadas en su momento, aunque alguna permanece todavía inédita y prácticamente desconocida, como los interesantes Diálogos de la juventud enamorada cuya fecha de composición podría considerarse no muy lejana a la de la obra que comentamos.

En cuanto a los nombres de los dialogantes, Cillenia y Selanio, no los hemos encontrado empleados en obras del periodo áureo y ofrecen a primera vista un aspecto cortesano y pastoril. Sin embargo, pueden admitir una interpretación mitológica, al menos en su etimología, origen que luego no vemos reflejado en el comportamiento ni en la ideología de los personajes del fragmento. Selanio parece tener relación con Selene, con una de las facetas de Diana, más conocida como la Luna, en tanto que Cillenia es la forma femenina de un apelativo del dios Mercurio; curiosamente el género de las divinidades aparece trastocado con relación a los personajes de esta obra, puesto que Selanio es el nombre del caballero cortesano que alaba la vida del campo y Cillenia la dama que sirve como interlocutora. No hemos localizado en Cervantes la forma "selanion, ni alguna otra similar, como "seleniow, en tanto que sí se encuentra usado el término "cillenio". Aparece en el Viaje del Parnaso cuando el dios Mercurio interpela a Cervantes en estos términos: "-iOh sobre humano y sobre / espíritu cilenio levantadow 15; más adelante Cervantes dice a Apolo: «Haz, joh señor!, que en público se lea / la lista que Cilenio llevó a España" ${ }^{16}$. Por último, en la misma obra, se lee: "Y díjole Cilenion ${ }^{17}$, etc. Como hemos indicado, se trata de una forma de referirse al dios Mercurio que, por supuesto, no es exclusiva de Cervantes, de tal manera que se puede encontrar en diversos autores más, como, por ejemplo, en los sonetos preliminares al Celidón de Iberia (1583), de Gonzalo Gómez de Luque; allí el capitán Juan de Quintana escribe: «La prole de Mnemosine se absconde: / El Cillenio, Minerva, el crespo Apolow ${ }^{18}$. Es posible que Cervantes escribiese también "Cillenio" en los ejemplos mencio-

15 Miguel de Cervantes, Viaje del Parnaso. Poesías completas, I, ed. Vicente Gaos. Madrid, Castalia, 1973, p. 61.

16 Ibid, p. 121.

17 Ibid., p. 154.

18 Gonzalo GÓmez de LuQue, Libro primero de los famosos hechos del príncipe Celidón de Iberia Alcalá, Juan Ińiguez de Lequérica, 1583, preliminares. 
nados antes ${ }^{19}$, con lo que la cercanía gráfica del término se acerca al que aparece en esta edición de Las semanas del jardín (véanse, por ejemplo, las pp. 1 y 10 del facsímil, donde aparece la palabra no abreviada y con Ç- inicial). Juan Pérez de Moya, en su Filosofía secreta (1585), explica que el término se aplica a Mercurio por su elocuencia y su sabiduría, con lo que puede establecerse cierta relación significativa con la dama Cillenia, que además de sabia, o interesada en la sabiduría y en el conocimiento de las cosas, es también elocuente, como se deja ver en el texto. «Dícenle Cillenio [a Mercurio], -escribe Pérez de Moya-, porque es dios de la elocuencia y sabiduría, y esta sabiduría obra todas las cosas sin manos, y a los que carecen de manos llaman en griego cylloe; otros dicen que se llamó así del monte Cillene, de Arcadia, donde nacióm ${ }^{20}$.

Por último, hay que señalar una cuestión relacionada con esta edición, aunque ajena a sus características específicas y al valor intrínseco de la misma: la dificultad de localización del libro, al menos para los interesados que se encuentran un tanto alejados de los grandes centros bibliográficos; de esta manera, en alguna ocasión, la búsqueda de tal obra, que podría calificarse casi de fantasmal, por lo inasible y evanescente que resultaba, ha supuesto una reiterada insistencia acerca de aquellos que pensaban que tal obra atribuida a Cervantes ni existía, ni mucho menos se contaba ya con una edición de la misma. Esto explica que, por ejemplo, en el somero escrito acerca de la actualidad bibliográfica en torno a Cervantes, aparecida en un reciente número de Quimera, se indique: «Daniel Eisenberg (Un fragmento de las "Semanas del jardin" de Cervantes, El Crotalón, 1989) pretende situar un diálogo pastoril como una parte de su anunciada y nunca publicada colección novelística Las semanas del jardin" ${ }^{21}$, donde interesa destacar que la referencia bibliográfica es casi la misma (excepto la fecha, 1986) que aparece en la página final de las publicaciones de «El Crotalón», catálogo inserto en El Crotalón. Anuario de Filología Española, 2, 1985, magnífica publicación que deseariamos ver reanudada. Tal información, además

19 Sin embargo no se encuentra reflejada esta suposición en la edición princeps del libro, cfr. Viage del Parnaso, compuesto por Miguel DE CERvantes SaAVedra, Madrid, por la Viuda de Alonso Martín, 1614, ff. 5 v, 38 v y 57 r., para las citas mencionadas en el texto. Tengo a la vista la edición facsímil de la obra, Madrid, Real Academia Española, 1990. Pudiera pensarse que la simplificación del grupo -ll- de procedencia culta y moderna, ajena a la palatalización, fuese obra de los tipógrafos del siglo xvil que verían anticuado el empleo de la grafía referida.

20 Juan Pérez de Moya, Filosofía secreta, Barcelona, Glosa, 1977, I, p. 263.

21 M.^ Eugenna Srbastún Tous, «Actualidad bibliográfica. Cervantes", Quimera, 102, 1991 , p. 59. 
de inexacta, puede considerarse más bien una referencia de oídas en torno a un tema tan polémico como éste.

Pero, a pesar de todo, si se consigue un ejemplar de esta obra (y esta dificultad pretende justificar la amplitud de algunas citas de la misma, incluidas a lo largo de esta reseña), las búsquedas, reiteraciones e insistencias, pueden darse por bien empleadas; en pocas ocasiones el lector actual tiene oportunidad de acercarse a un texto clásico tan jugoso, tan fresco y tan desconocido en una edición tan correcta y sugerente.

Antonio CRUZ CASADo 